\title{
The Importance of Statistical Analysis in the Development of the Capabilities of Faculty Members in the BAU
}

\author{
M Rasheed Noha ${ }^{1, *}$ \\ ${ }^{1}$ Al-Huson University College, AL Balqa' Applied University, P.O.Box 50, Al-Huson, Irbid, \\ Jordan \\ *Correspondence: Al-Huson University College, AL Balqa' Applied University, P.O. Box 50, \\ Al-Huson, Irbid, Jordan E-mail: alrashidnm@hotmail.com
}

Received: December 18, 2012 Accepted: April 11, 2013 Published: June 24, 2013

doi:10.5296/ije.v5i2.2905 URL: http://dx.doi.org/10.5296/ije.v5i2.2905

\begin{abstract}
This study seeks to assess the needs of faculty members at the University of Baku Applied in the use of statistical analysis software and activate it to improve performance, through polling on how to activate the use of these programs in the academic field and assess the needs for training, to provide an opportunity for studies to come through which to work on the development of training programs well and on a scientific basis.

A questionnaire was built has been distributed to more than 200 faculty members at the University of Baku Applied who are registered in the register of the university in the second semester of the academic year 2011-2012 as: professor, assistant professor, associate professor, lecturer, teacher, and after analyzing 175 questionnaires obtained by the researcher, the results showed that the use of members of the statistical analysis programs in total is low. Has been using a set of tests conducted to identify the extent and the effect of the independent variables on the axes of the study like gender, years teaching experience, and academic rank, and use of sample for statistical analysis applications and assess their needs for training. Also a set of recommendations was added. The most important ones were the need for future studies in this area, and the need for planning for training programs in the field of statistical analysis in order to improve the performance of faculty members, and so they can use these applications in all areas, both in the academic field, or in the field of scientific research.
\end{abstract}

Keywords: statistical analysis; questionnaire; training; SPSS program; quarterly grades and skills improvement 


\section{Introduction}

The development of the performance of faculty members has great importance at the local level and the Arab world, especially with the advent of modern developments in the field of communication and information technology, and the emergence of the concept of total quality and academic assessment, and self-development, And interaction with the outside world that he no longer believes in the geographic boundaries, nor spatial frameworks, and the social organizations, but off to the World Unlimited, and believes in globalization as a philosophy of life, and a system of living.

Thus began the educational institutions at all levels, especially higher education institutions emphasizing the importance of the continued development not only in the information knowledge which represents the essential foundation for university education, but in the way the information is transferred in, and the best way to speed interaction with it, and bring it closer, with an emphasis on the receiving door was open knowledge without borders so the forum has the right to acquire knowledge, and interact with it in line with trends, desires, and abilities.

This is in fact doubles the voltage on the two works in the higher education sector to adopt a range of training programs and ask the universities compete to provide rehabilitation programs, and development for its employees, also exchanges among these programs and encourages the workers to enroll, both of whom recently graduated or who enjoy the experience of a long process.

\subsection{Problem of the study}

The problem of the study is in being a serious attempt to determine the needs of faculty members at the University of Balqa Applied in the field that is one of the most important areas of training that training efforts should guide to, and that is area to analyze the results of the quarterly grades for students.

\subsection{Objectives of the study}

This study aims to explore the experiences of faculty members at the University of Balqa Applied to identify training needs in the area of statistical analysis, and practice applied to methods and applications of these techniques, in order to reach many of the proposals that will help them develop their skills in these areas.

This main objective is branching for many sub-goals which include:

1) Identify the most important personality traits for faculty members working at Balqa Applied University in terms of gender, academic rank, practical experience in the field of teaching.

2) Get over their use of a range of practical applications and effective programs in the field of statistical analysis.

3) Poll sample for estimating their needs for training in statistical analysis applications. 


\subsection{Study questions}

This study seeks to answer the following questions:

1) How far is the use of faculty members at the University of Balqa Applied for statistical analysis applications?

2) To what extent needs of faculty members in the Balqa Applied University, from their point of view, to train on SPSS for statistical analysis applications?

3) What are the most important proposals derived from the field study for the development of the skills of faculty members in the Balqa Applied University in the field of statistical analysis?

\subsection{The importance of the study}

The review and assess of the needs of faculty members in higher education Occupies an important place in the cord of higher education, and an important indicator as a tool to work on the development of performance, and upgrading work. That is why all institutions of higher education at various levels establish sophisticated software, and inflict its specialized centers serving institutions such programs.

Improving the performance of faculty members represents a necessary and urgent need due to the fact that university teaching has become a profession that requires skills-based on training and education beside it needs to know the theory, especially in light of the large population growth experienced by all human societies, and the explosion of knowledge and technical that science is provided in, not through closed study rooms, but through open schools students can learn from what they want without spatial barriers, social norms, or cultural constraints (8).

The study is an integral part of the ongoing review adopted by the BAU once in a while, like all institutions of higher education in all world, this study also will seek to identify some of the training programs that can contribute effectively to the development of the performance of faculty members at the University of Balqa Applied, and what applies to employees of this university can be circulated to employees of Jordanian universities at least because of the similarity between the performance of the employees of these universities.

\subsection{Limits of the study}

This study was conducted in the second semester of the academic year 2011-2012, and has been confined to employees of Balqa Applied University faculty members (Professor, Associate Professor, Assistant Professor, Lecturer, Teacher) of male and female and various practical experiences

\subsection{Terms of the study}

Researcher selected the following procedural definitions of the terms of the study:

1) Statistical analysis: defined as a set of methods used to process large amounts of data and to report general trends .It is particularly useful when dealing with data and provides 
ways to provide an objective report on unusual method was used. (5)

2) Training needs: a group of changes required to make in the individual and for his expertise, information, performance, behavior and trends to make him fit for a job or higher performance functions and duties of his current job efficiently. (Al-Abd Al-Ghafoor, 2002)

\subsection{The study population and appointed}

The study population consists of all faculty members at the University of Baku Applied registered owners of all colleges in the second semester 2011-2012, totaling in that period () and to varying degrees (assistant professor, associate professor, professor, lecturer, teacher) according to data obtained by the researcher from the university administration.

Due to the researcher's desire to investigate the views of all members have adopted, the research community as a whole was considered to take a sample from his study, and he distributed the questionnaire to some faculty members with the middle of the second semester of the academic year 2011-2012, as cited in Table 1.

Table 1: Describe members of the community: numbers and percentages

\begin{tabular}{llll}
\hline Independent Variable & & $\mathrm{N}$ & Frequency \% \\
\hline Gender & Male & 118 & 67.4 \\
Class & Female & 48 & 27.4 \\
& Prof & 4 & 2.4 \\
& Share & 18 & 10.3 \\
& Ass. & 72 & 41.1 \\
& Teach & 42 & 24 \\
Years of experience & Lect. & 35 & 20 \\
& $1-5$ & 53 & 30.3 \\
& $6-10$ & 28 & 16 \\
& $11-15$ & 12 & 6.9 \\
\hline
\end{tabular}

This table represents an analysis of the members of the community (demographic variables). Numbers and ratios.

\section{Study Methodology}

The researcher considered the descriptive method in the study, from which the poll faculty members at the University of Balqa Applied on the extent of their use of statistical analysis software in their teaching, And the extent of their knowledge of tools and applications that have been presented, and the use of their opinions to determine the extent of their need for training on all of them.

A special questionnaire tool was built for this purpose through which the collection of these views, compilation and analysis were done using an eighteenth release SPSS program for 
these operations.

\subsection{Study tools}

The researcher used a questionnaire consists of three parts:

The first part contains the initial data for the research sample, which were represented in gender, academic rank, and number of years of experience for the faculty member. Part tow also includes inquiry about the use of statistical analysis software applications.

The third part included a sample estimate of the training needs to identify the statistical analysis applications that have been mentioned in the second part of the questionnaire through the identification of one of the values.

Believe Tool:

The veracity of the data collection tool (questionnaire) was confirmed by verifying honesty virtual offer on a number of specialists in the field of scientific research and in the field of statistical analysis. Their opinions were taken into consideration where adjustment of some phrases minor amendment was included.

Stability of the Tool:

Stability of information gathering tool has been verified by using Cronbach's alpha test This test has shown considerable consensus among the phrases of questionnaire in every part, where the result was high (Table 2).

Table 2: Alpha values for Cronbach's alpha test (reliability)

\begin{tabular}{ll}
\hline Alpha questionnaire & 0.76 \\
Alpha first axis & 0.44 \\
Alpha second axis & 0.54 \\
Alpha third axis & 0.37 \\
Alpha fourth axis & 0.69 \\
\hline
\end{tabular}

\section{Previous Studies}

1) Al- Shehry, Mansour Bin Ali. (1425). Study the use of faculty members at the University of King Saud to information and communication technologies in the educational process. Symposium on the development of faculty members in higher education institutions (and development challenges) College of Education - King Saud University in the period 2-3/11/1425 (published research).

2) Adel bin Ahmed Babtain study, which aimed to identify the most important problems of statistical significance in educational research and to reach alternative solutions in Umm Al-Qura University. (Al-Nasser, 2007)

3) Altowjry, Abdullah. Mohammed. (2005). Reforming higher education in Saudi Arabia: The use of telecommunications technology. Unpublished master degree submitted to 
Rochester Institute of Technology. Ny, USA Jacobsen, D. Michele. (1998).

4) Savery (2002) (Faculty \& Students Perceptions of Technology Integration in Teaching)

\section{Statistical Analysis}

Display and analysis and interpretation of the results:

SPSS program was used to analyze the results of the study and answer all the questions that were arranged as follows:

First: the raw data of the study sample:

The sample study, which has mobilized questionnaires consistent with the methodology of the study 175 cases, after excluding questionnaires uncompleted, which showed lack of credibility in the response, choosing a response in all the paragraphs of the questionnaire, or failure to complete all items in the form

As can be seen from Table (1) the majority of the study sample were males (67\%), and the proportion of females does not exceed (28\%). In terms of the distribution of the quality of participants regarding degree, it is clear from Table (1) that the distribution showed that the majority of the participants are assistant professors $(41.1 \%)$ who often represent the largest number in each university, while the percentage of participants who hold associate professor degree $(10.3 \%)$. At last in terms of the distribution of the quality of the participants regarding practical experience, it is clear from Table (1), that the distribution showed that the majority of the participants were those who have experience (1-5) years $(30.3 \%)$, while the percentage of participants who have experience of 15 years and above (4\%). (6)

Second: The answers of the axes of the study:

The results were reviewed by the researcher of this study according to the sequence of axes that have been monitored in the title themes, are as follows:

Answer of the first axis: (Importance of statistical analysis for a faculty member at the University of Balqa Applied).

Table (3) shows the analysis of the answers to questions of the first axis and its association with the independent variables. It gives statistically significant differences depending on academic rank that indicates that statistical analysis has its importance for faculty member based on academic rank. Through the value of the significance level that was equal to 0.044. This value is less than 0.05 that indicates statistically significant differences in academic rank and its relation to the first axis my .E the more academic rank a faculty member has, the more its need for statistical analysis increases. (Al-Nasser, 2007)

Answers of the second axis: (Role of statistical analysis in dealing with quarterly marks for students) 
Table 3: Results of the analysis of the first axis and its relation to the independent variables

\begin{tabular}{llccccc}
\hline $\begin{array}{l}\text { Independent } \\
\text { Variable }\end{array}$ & & $\mathrm{N}$ & $\mathrm{M}$ & Std. & Test & P-value \\
\hline Gender & Male & 118 & 2.24 & 0.53 & $\mathrm{~T}(164)=-0.994$ & 0.322 \\
& Female & 48 & 2.33 & 0.52 & & \\
Class & Prof & 4 & 2.25 & 0.70 & $\mathrm{~F}(4,166)=2.5$ & 0.044 \\
& Share & 18 & 2.08 & 0.71 & & \\
& Ass. & 72 & 2.16 & 0.48 & & \\
& Teach & 42 & 2.45 & 0.49 & & \\
Exp & Lect. & 35 & 2.30 & 0.56 & & \\
& $1-5$ & 53 & 2.24 & 0.516 & $\mathrm{~F}(3,96)=1.21$ & \\
& $6-10$ & 28 & 2.41 & 0.54 & & \\
& $11-15$ & 12 & 2.52 & 0.44 & & \\
& $15+$ & 7 & 2.40 & 0.80 & & \\
\hline
\end{tabular}

Table (4), which shows the analysis of the answers of the second axis and its association with the independent variables, shows that there are no statistically differences based on any of the Independent items. This means, based on the opinion of respondents there was no role for statistical analysis in dealing with quarterly marks. (Al-Nasser, 2007)

Table 4: Results of the second axis and its association with the independent variables

\begin{tabular}{llccccc}
\hline $\begin{array}{l}\text { Independent } \\
\text { Variable }\end{array}$ & & $\mathrm{N}$ & $\mathrm{M}$ & $\mathrm{Std}$. & $\mathrm{T}$ & Pest \\
\hline Gender & Male & 118 & 2.19 & 0.73 & $\mathrm{~T}(164)=0.129$ & 0.89 \\
& Female & 48 & 2.18 & 0.88 & & \\
Class & Prof & 4 & 2.25 & 0.95 & $\mathrm{~F}(4,166)=1.47$ & 0.212 \\
& Share & 18 & 2.16 & 0.78 & & \\
& Ass. & 72 & 2.12 & 0.69 & & \\
& Teach & 42 & 2.38 & 0.87 & & \\
& Lect. & 35 & 1.98 & 0.61 & & \\
& $1-5$ & 53 & 2.12 & 0.77 & $\mathrm{~F}(3,96)=0.588$ & \\
& $6-10$ & 28 & 2.34 & 0.71 & & \\
& $11-15$ & 12 & 2.27 & 0.908 & & \\
& $15+$ & 7 & 2.33 & 0.666 & & \\
\end{tabular}

Answers of the third axis: (Role of statistical analysis in the research results for a faculty member)

We can notice from Table (5) the presence of statistically significant differences depending on the factor of academic rank, years of experience, where the value of the level of significance for each of them respectively 0.018 and 0.005 and these values are less than 0.05 , means statistical analysis has a role in the results of research for a faculty member based on academic rank and years of experiences higher the academic rank of faculty member and the increased years of experience are, his need for statistical analysis for use in his own research, increases. (Al-Nasser, 2007) 
Table 5: Results of the third axis and its association with the independent variables

\begin{tabular}{llccccc}
\hline $\begin{array}{l}\text { Independent } \\
\text { Variable }\end{array}$ & & $\mathrm{N}$ & $\mathrm{M}$ & $\mathrm{Std}$. & Test & P-value \\
\hline Gender & Male & 118 & 2.49 & 0.66 & $\mathrm{~T}(164)=0.129$ & 0.89 \\
& Female & 48 & 2.61 & 0.74 & & \\
Class & Prof & 4 & 2.81 & 0.42 & $\mathrm{~F}(4,166)=3.08$ & 0.018 \\
& Share & 18 & 2.77 & 0.78 & & \\
& Ass. & 72 & 2.40 & 0.70 & & \\
& Teach & 42 & 2.73 & 0.65 & & \\
Exp & Lect. & 35 & 2.34 & 0.53 & & \\
& $1-5$ & 53 & 2.43 & 0.53 & $\mathrm{~F}(3,96)=4.49$ & \\
& $6-10$ & 28 & 2.60 & 0.88 & & \\
& $11-15$ & 12 & 3.08 & 0.65 & & \\
& $15+$ & 7 & 3.10 & 0.57 & & \\
\hline
\end{tabular}

Answers of the fourth axis: (The most important proposals to help the faculty member to do his own statistical analysis)

Notice from Table (6) that there exist significant statistically differences depending on years experience through the value of the significance level that was equal to 0.009 which is less than 0.05 . This means that the more years of experience to the faculty member encouraged his own statistical analysis. (Al-Nasser, 2007)

Table 6: Results of the fourth axis and its association with the independent variables

\begin{tabular}{llccccc}
\hline $\begin{array}{l}\text { Independent } \\
\text { Variable }\end{array}$ & & $\mathrm{N}$ & $\mathrm{M}$ & Std. & Test & P-value \\
\hline Gender & Male & 118 & 2.00 & 0.84 & $\mathrm{~T}(164)=0.30$ & 0.765 \\
& Female & 48 & 1.95 & 0.73 & & \\
Class & Prof & 4 & 2.08 & 0.83 & $\mathrm{~F}(4,166)=1.5$ & 0.205 \\
& Share & 18 & 2.07 & 0.88 & & \\
& Ass. & 72 & 1.95 & 0.75 & & \\
& Teach & 42 & 2.19 & 0.83 & & \\
Exp & Lect. & 35 & 1.76 & 0.81 & & \\
& $1-5$ & 53 & 1.84 & 0.70 & $\mathrm{~F}(3,96)=4.102$ & \\
& $6-10$ & 28 & 2.25 & 0.85 & & \\
& $11-15$ & 12 & 2.41 & 0.75 & & \\
& $15+$ & 7 & 2.61 & 0.70 & & \\
\hline
\end{tabular}

Analysis shows that the sample suggests the first solution that is to join a training course posed from an educational institution for the training of the statistical analysis, and the third solution that is to have an office for advice on statistical analysis within the institution.

The questionnaire contained a paragraph of four questions that have one of two answers: (yes, no) about things that may have prevented a faculty member analyze the results of his former students, namely: 
1) Should do the analysis or not.

2) Time is enough for it or not.

3) The necessary technologies needed are provided or not.

4) Ability of a faculty member of the results of the analysis recruitment later or not.

The answers of these questions have been linked with the four previously mentioned themes as follows:

Table (7) shows the relationship of the answers of these questions with the four axes, one by one.

- Considering the first one, it is shown that statistical analysis is important for the faculty members but there are things hindering him like not having time, lack of technologies required and inability to recruitment results in coming times.

- Regarding the second axis, again in the absence of the necessary techniques for analysis and inability recruitment results in the futures, take place in affecting dealing with students quarterly marks.

- Regarding the third axis, the table shows there are no significant statistical differences between the axis and its association with these questions, that is nothing affects the faculty member while dealing with this research results.

- The same result was found regarding the fourth axis, where there are no significant differences between the axis and its association with these questions. (Al-Nasser, Amjad, 2007)

Table 7: Results of the four axes and their association with the independent variables

\begin{tabular}{llcccccccc}
\hline Q & Ans. & Axis1 & P-value & Axis2 & P-value & Axis3 & P-value & Axis4 & P-value \\
& & $\mathrm{N}$ & & $\mathrm{N}$ & & $\mathrm{N}$ & & $\mathrm{N}$ & \\
\hline Q1 & Yes & 95 & 0.032 & 95 & 0.97 & 95 & 0.327 & 95 & 0.385 \\
& No & 77 & & 77 & & 77 & & 77 & \\
Q2 & Yes & 102 & 0.000 & 102 & 0.106 & 102 & 0.115 & 102 & 0.369 \\
& No & 68 & & 68 & & 68 & & 68 & \\
Q3 & Yes & 77 & 0.003 & 77 & 0.001 & 77 & 0.356 & 77 & 0.491 \\
& No & 92 & & 92 & & 92 & & 92 & \\
Q4 & Yes & 105 & 0.000 & 105 & 0.000 & 105 & 0.107 & 105 & 0.329 \\
& No & 60 & & 60 & & 60 & & 60 & \\
\hline
\end{tabular}

\section{Results and Recommendation}

\subsection{Results}

1) Results of analysis of the four axes answers with the academic rank of the faculty members: 
The study showed that there are significant statistical differences between the rates of answers of both of (first and third) axes and the academic rank. The rates for the first and third axes are given in details in table (3) and table (5) respectively.

On the other hand the study showed there are no significant statistically differences between rates of answers of (second and fourth) axes and the academic rank as shown in tables 4 and 6 , means the analysis has the same importance for different academic ranks while dealing with the quarterly grades or choosing one of the proposals included in the questionnaire.

2) Results of analysis of the four axis answers with the gender of the faculty members:

It was found that there are no significant statistically differences between all rates of answers of each of the four axes and the gender, that indicates that statistical analysis is equally important for males as females.

3) Regarding years of experience of the faculty members, tables (3) and (4) show that there are no significant differences between the rates of answers of the (first and second) axes and years of experience. While there are between these years and rates of the (third and fourth) axes with averages shown in tables (5) and (6).

4) Finally it was found that the faculty member is facing some computer problems when using computers in the statistical analysis and that his need lies in judgment on the effectiveness of teaching strategy used by comparing results before and after use of the strategy. Also that the impediment for the faculty member in analysis of his own research is that the wages of the analysis are expensive in private offices and the most important proposals for him are to join a training course posed by the educational institution and to have an office for advice on statistical analysis within the institution.

\section{Recommendations}

Through review of the content of the study for assessing the needs of faculty members at the University of Balqa Applied in the field of information technology in the light of their ability to use these methods and applications, and through their opinions on the most important difficulties that could hinder this use, the researcher recommends the following:

1) The importance of further field studies in this area.

2) Interest in the field of statistical analysis software applications as areas appoints university faculty member to take advantage of them in the development of performance, and the need for planning training programs in these applications to suit the needs of faculty members, particularly in the methods that have been reviewed.

3) Interest in future studies in the area of needs assessment of faculty members in the field of software statistical analysis or in other areas that can work on the development of performance of faculty members to achieve the highest possible quality in performance and being able to work, whether in the field of teaching or in the field of scientific research and community service. 
4) The provision of training programs for faculty members in the field of statistical analysis software, and choose the times commensurate with their leisure time members, the start of the school year, or after the completion of the tests before the start of the annual leave of the members.

5) Provide technical support to members on the days of the week and through specialists can communicate with them and modes of modern technology (email, mail groups, chat, forums, etc.)

6) Providing the tools and computer equipment to all members, with the provision of communication with both local databases, or the World encourages members to use communication technology, whether on campus or with external actors.

\section{References}

Al- Shehry, Mansour Bin Ali. (1425). Study the use of faculty members at the University of King Saud to information and communication technologies in the educational process. Symposium on the development of faculty members in higher education institutions (and development challenges)_College of Education - King Saud University in the period 2-3/11/1425 (published research).

Babtain, Adel bin Ahmed. Identify the most important problems of statistical significance in educational research in Umm Al-Qura University. Uqu. Edu. Sa/ majalat/humanities, 2 vol 14/bo8 htm

Altowjry, Abdullah Mohammed. (2005). Reforming higher education in Saudi Arabia: The use of telecommunications technology. Unpublished master degree submitted to Rochester Institute of Technology. Ny, USA Jacobsen, D. Michele. (1998).

Savery. (2002) (Faculty \& Students Perceptions of Technology Integration in Teaching)

Al Zaher, Ali. Nasser. (1425). A proposed program for the development of academic 4 practices for faculty and higher education institutions in Saudi Arabia. Symposium on the development of faculty members in higher education institutions. 24 to 25 / 10 / 1425 $B E$ in the College of Education. King Saud University

Al-Nasser, Amjad. (2007). Lecture notes in using statistical analysis spss. Irbid: the auther.

Aljundi, Alia. Abdullah. (2000). The importance of digital technology in the field of learning from the point of view of faculty members in some Saudi universities. Umm Al-Qura University journal of education, social and human sciences, 12(2), 11-22.

Al- Joudi, Mohammed. Ghazi. (1424). Check the needs of faculty members and students of the college of teachers in the Kingdom of Saudi Arabia training on the use of computers. Summary of doctoral thesis magazine teachers colleges, 3(1), 184-191.

Al-Abd Al-Ghafoor, Fawzia. Yousef. (2002). The problems facing the faculty member and the impact on the level of job performance. Faculty of basic education in the State of Kuwait, the Arabian Gulf, Riyadh, No. 85. 


\section{Copyright Disclaimer}

Copyright reserved by the author(s).

This article is an open-access article distributed under the terms and conditions of the Creative Commons Attribution license (http://creativecommons.org/licenses/by/3.0/). 